\title{
Bromelain has significant clinical benefits after extraction of the third molar during chemotherapy in patients with hematologic tumor
}

\author{
YI TAN and PING LI \\ Department of Stomatology, Hubei Maternal and Child Health Care Hospital of China, Wuhan, Hubei 430070, P.R. China
}

Received April 10, 2017; Accepted August 22, 2017

DOI: $10.3892 / \mathrm{ol} .2017 .7673$

\begin{abstract}
The purpose of this study was to investigate the application of bromelain in the treatment of pain, swelling, and limited mouth opening in patients with hematologic tumor after extraction of the third molar during chemotherapy. We recruited 72 patients with hematologic tumor who were treated by oral and maxillofacial surgery in our hospital, and third molar extraction was performed under local anesthesia. After extraction, patients in the control group were treated with cold - hot compress and patients in the experimental group were treated by oral administration of bromelain. One, three, and seven days after extraction, pain, swelling, and mouth opening in the experimental group improved compared to the control group. Additionally, the levels of IL-25 and TNF- $\alpha$ in the experimental group were significantly lower than in the control group, suggesting less inflammatory response. On the other hand, EGFR and $\beta$-FGF were significantly higher in the experimental group, supporting the activation of tissue repair pathways. Quality of life scores were significantly better in the experimental group. Overall, bromelain improves the quality of life, alleviates pain, swelling, and mouth opening, and effectively prevent postoperative complications in patients with hematologic tumors after third molar extraction during chemotherapy.
\end{abstract}

\section{Introduction}

Third molar extractions are one of the most common and basic outpatient interventions in oral and maxillofacial surgery (1). With the continuous development of medical technologies

Correspondence to: Dr Ping Li, Department of Stomatology, Hubei Maternal and Child Health Care Hospital of China, 745 Wuluo Road, Hongshan, Wuhan, Hubei 430070, P.R. China

E-mail: fqxf0057@163.com

*Contributed equally

Key words: bromelain, hematological tumor, chemotherapy, third molar extraction, postoperative complications and research on new devices, minimally-invasive tooth extraction has been widely applied. Simplified procedures and shorter surgery relieve pain and reduce complications. However, patients still suffer some pain, swelling, limitation in mouth mobility, and other symptoms after surgery $(2,3)$. Hematological tumors are common malignant tumors, including various leukemias, malignant lymphomas, and multiple myeloma. The main treatment for these tumors is chemotherapy, which causes immunosuppression and reduced immunity. Dental treatment for patients with hematological tumors should be conducted during chemotherapy to reduce the probability of infections. This can effectively prevent the incidence of various complications that can negatively impact the quality of life $(4,5)$. Reducing dental malaise and postoperative complications is a critical issue for oral and maxillofacial surgery doctors. Bromelain is the generic term for a series of proteases found in the fruit and stem of pineapples. Bromelain has anti-inflammatory properties and can promote wound healing (6). Oral administration of bromelain during the perioperative period for third molar extractions can effectively improve quality of life (7). Herein, we present research conducted on the administration of bromelain during third molar extraction in chemotherapy patients with hematological tumors. We report good efficacy for bromelain in reducing pain and preventing postoperative complications.

\section{Materials and methods}

Patient data. We recruited 72 patients with hematological tumors accompanied by mandibular-impacted third molar who met the standard hemogram from January 2015 to December 2015. Inclusion criteria: diagnosis of hematological tumor; white blood cell count $3-12 \times 10^{9} / 1$, platelet count $\geq 60 \times 10^{9} / 1$, absolute neutrophil count $\geq 10^{9} / 1$; average score of the difficulty of mandibular impacted third molar extraction $\geq 14$, patients had difficulties with tooth extraction; and informed consent form signed by patients. Exclusion criteria: contraindications of surgery; long-term administration of medication, recent administration of glucocorticoids, antibiotics, or anodyne; recurrent pericoronitis of the impacted tooth; moderate caries of the wisdom tooth and adjacent teeth; periapical periodontitis, pulpitis, or periodontitis. The study was approved by the Ethics Committee of Hubei Maternal and Child Health Care Hospital of China. We randomly divided 
Table I. General clinical data.

\begin{tabular}{|c|c|c|c|c|}
\hline Item & Control group $n=36$ & Observation group $n=36$ & $\mathrm{t} / \chi^{2}$ & P-value \\
\hline Sex (male/female) & $20 / 16$ & $22 / 14$ & 0.057 & 0.811 \\
\hline Age (year) & $15-45$ & $16-45$ & & \\
\hline Average age (year) & $23.76 \pm 5.48$ & $24.35 \pm 5.57$ & 0.453 & 0.651 \\
\hline BMI $\left(\mathrm{kg} / \mathrm{m}^{2}\right)$ & $22.13 \pm 3.45$ & $22.76 \pm 3.38$ & 0.783 & 0.436 \\
\hline \multicolumn{5}{|c|}{ Hematological tumor classification (n, \%) } \\
\hline Acute lymphoblastic leukemia & $13(36.11)$ & $12(33.33)$ & 0.585 & 0.964 \\
\hline Acute non-lymphocytic leukemia & $11(30.56)$ & $9(25.00)$ & & \\
\hline Aplastic anemia & $5(13.89)$ & $6(16.67)$ & & \\
\hline Non-Hodgkin's lymphoma & $4(11.11)$ & $5(13.89)$ & & \\
\hline Langerhans cell histocytosis & $3(8.33)$ & $4(11.11)$ & & \\
\hline Impacted type (n, \%) & & & 0.224 & 0.894 \\
\hline Vertical impaction & $18(50.00)$ & $16(44.44)$ & & \\
\hline Central loxosis impaction & $10(27.78)$ & $11(30.56)$ & & \\
\hline Level of impaction & $8(22.22)$ & $9(25.00)$ & & \\
\hline
\end{tabular}

patients into equal experimental and control groups, each with 36 patients. The double-blind method was used to conduct perioperative treatment for patients in the two groups. General clinical data for the patients in the two groups were statistically comparable (Table I).

Preoperative preparation. All patients received routine examination and dental X-ray film before surgery. The degree of swelling, index of limitation of mouth opening, and related data were measured before surgery. Three medical staff independently measured the data to obtain the average. Patients in the experimental group started to take bromelain entericcoated capsules orally (Guangxi Province Nanning City Baihui Pharmaceutical Group, approval number: MPN- H45021171) one day before surgery. Dosage: 30,000 units every time, three times/day. Chloroprocaine hydrochloride (4 $\mathrm{ml}$ of $2 \%$ ) and epinephrine $(1: 100,000)$ were used for inferior alveolar nerve block anesthesia.

Surgical methods. We first conducted routine disinfection and drape, and then proceeded with traditional chisel, standing out method and bone removing method. After extraction, fragments in the alveolar fossa were cleared. We used normal saline to wash and then closed the wound. Patients who had their gingival open received sutures in an open manner. Sterilized cotton roll was used to compress the wound. Patients were told to tightly bite the roll for $30 \mathrm{~min}$ and then gently spit it out.

Postoperative treatment. The control group received cold-hot compress for two days. The experimental group continued to receive oral bromelain enteric-coated capsules on the day of the surgery. Dosage: 30,000 units every time, three times/day, continuous administration for three days. When patients suffered adverse reactions, like nausea, allergy, or vomiting, they immediately stopped the treatment and quit the study.
Detection of indexes and evaluation. The visual analog score (VAS) was adopted to evaluate the pain degree of patients. The score range was 0-10 (0 for no pain and 10 for intolerable severe pain). Standard: no pain: $0-1$ points for no pain or little pain or pain hard to feel; mild: $2-3$ points for tolerable pain that did not affect sleep; moderate: 3-6 points for pain that altered normal daily activities and sleep; severe: $\geq 7$ points for intolerable pain, patients took ibuprofen sustained release capsule or return for a visit.

Swelling degree. The line connecting method was used to measure distances. CT distance: the distance of the skin surface from the tragion ( $\mathrm{T}$ point) on the affected side of the cheek to the cheilion ( $\mathrm{C}$ point) on the same side. ME distance: the distance on the skin surface from the external canthus point on the same side (E point) to the mandibular angle point (M point). Value difference of $\mathrm{CT}+\mathrm{ME}$ before and after surgery indicated the swelling degree.

Limitation of mouth opening. We measured the distance from the upper central incisor margin to the lower at the biggest positive mouth opening state before and after surgery. Distance differences before and after surgery indicated the limitation of mouth opening degree.

Blood and saliva samples were collected on postoperative days 1,3 , and 7. ELISA was used to determine the expression of IL-25 in gingival crevicular fluid and levels of TNF- $\alpha$, EGFR, and $\beta-F G F$ in serum. Kits for detection of IL-25, TNF- $\alpha$, EGFR, and $\beta$-FGF were provided by Rapid Bio Company. Operations were conducted strictly according to instructions of the kits. OD value was measured at $450 \mathrm{~nm}$ wavelength.

One week after surgery, the quality of life after tooth extraction was evaluated by the modified postoperative symptom severity scale (PoSSe) method. Patients were scored in 7 dimensions: food, language, feeling, swelling, pain, nausea, and daily living. PoSSe value was negatively correlated with the living quality of patients. 
Table II. Pain by VAS scale.

\begin{tabular}{lcccc}
\hline Group & Cases & Postoperative day 1 & Postoperative day 3 & Postoperative day 7 \\
\hline Experimental & 36 & $5.35 \pm 1.14$ & $4.06 \pm 1.13$ & $2.23 \pm 1.02$ \\
Control & 36 & $6.06 \pm 1.23$ & $4.73 \pm 1.25$ & $2.76 \pm 1.17$ \\
t-value & & 2.540 & 2.368 & 2.049 \\
P-value & 0.013 & 0.019 & 0.044 \\
\hline
\end{tabular}

Table III. Swelling.

\begin{tabular}{lcccc}
\hline Group & Cases & Postoperative day 1 & Postoperative day 3 & Postoperative day 7 \\
\hline Experimental & 36 & $2.23 \pm 0.34$ & $1.23 \pm 0.13$ & $0.23 \pm 0.11$ \\
Control & 36 & $2.85 \pm 0.43$ & $1.98 \pm 0.27$ & $1.01 \pm 0.37$ \\
t-value & & 6.786 & 15.017 & 12.124 \\
P-value & & $<0.0001$ & $<0.0001$ & $<0.0001$ \\
\hline
\end{tabular}

Table IV. Limitation of mouth opening degree.

\begin{tabular}{lcccc}
\hline Group & Cases & Postoperative day 1 & Postoperative day 3 & Postoperative day 7 \\
\hline Experimental & 36 & $2.15 \pm 0.34$ & $1.16 \pm 0.33$ & $0.43 \pm 0.12$ \\
Control & 36 & $2.76 \pm 0.53$ & $1.83 \pm 0.45$ & $1.16 \pm 0.27$ \\
t-value & & 5.812 & 7.204 & 14.824 \\
P-value & & $<0.0001$ & $<0.0001$ & $<0.0001$ \\
\hline
\end{tabular}

Statistical analysis. Data were processed by SPSS 19.0 statistics software. Measurement data were expressed as mean \pm standard deviation and t-test was used to compare groups. Enumeration data were processed by $\chi^{2}$ test. $\mathrm{P}<0.05$ was considered to indicate a statistically significant difference.

\section{Results}

Pain after molar surgery. We compared several scores for the experimental and control groups after molar surgery. According to the VAS results of pain after surgery, the pain decreased in both groups from day 1 to day 7 after surgery (Table II). However, the experimental group exhibited significantly lower scores at each time point compared to the control group (Table II), indicating more efficient pain reduction.

Swelling after molar surgery. In terms of swelling degree after surgery, swelling decreased in both groups from day 1 to day 7 after surgery (Table III). However, the experimental group exhibited significantly lower swelling than the control group at each time point (Table III), indicating more efficient swelling management.

Limitation of mouth opening. The limitation of mouth opening degree decreased in both groups from day 1 to day 7 after surgery (Table IV). However, the experimental group exhibited significantly lower scores than the control group at each time point (Table IV), indicating more efficient functional recovery after surgery.

Values of molecular markers. We next compared the concentration of IL-25 in gingival crevicular fluid and levels of TNF- $\alpha$, EGFR, and $\beta$-FGF in serum. In the experimental group, the levels of IL-25 on postoperative days 1, 3 and 7 were $239.43 \pm 7.24,201.67 \pm 7.23$, and $193.45 \pm 6.25 \mathrm{pg} / \mathrm{ml}$. In the control group, the levels of IL-25 were $289.63 \pm 9.27$, $243.54 \pm 8.46$, and $203.47 \pm 7.36 \mathrm{pg} / \mathrm{ml}$. The values in the experimental group were significantly lower than in the control group, although the difference was smaller at day 7 (Fig. 1).

In the experimental group, the levels of TNF- $\alpha$ level were $23.36 \pm 3.42,16.36 \pm 2.27$, and $8.43 \pm 1.34 \mathrm{pg} / \mathrm{ml}$. In the control group, the levels of TNF- $\alpha$ were $30.78 \pm 3.42,24.56 \pm 2.68$, and $18.62 \pm 2.46 \mathrm{pg} / \mathrm{ml}$. The values in the experimental group were significantly lower than in the control group at each time point and the differences were the same over time (Fig. 2).

The levels of EGFR in the experimental group were $1.53 \pm 0.22,1.97 \pm 0.23$, and $3.46 \pm 0.29 \mathrm{ng} / \mathrm{ml}$. The levels of EGFR in the control group were $0.94 \pm 0.18,1.24 \pm 0.13$, and $1.67 \pm 0.18 \mathrm{ng} / \mathrm{ml}$. The values in the experimental group were significantly higher than in the control group at each time point and the differences grew over time (Fig. 3).

The levels of $\beta$-FGF in the experimental group were $23.43 \pm 3.42,63.97 \pm 4.23$, and $89.46 \pm 6.29 \mathrm{pg} / \mathrm{ml}$. In the control group, the levels were $17.53 \pm 2.74,33.56 \pm 3.43$, and 


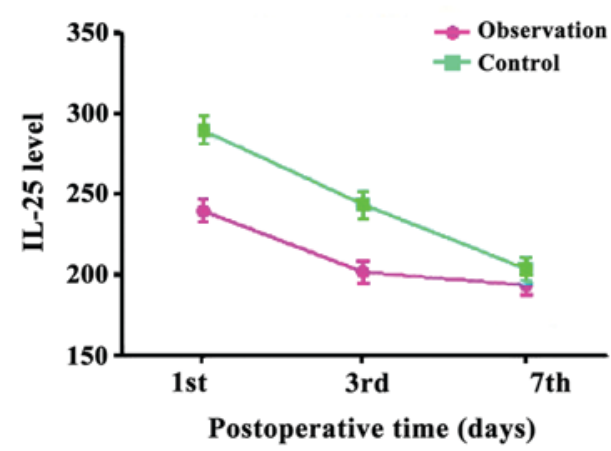

Figure 1. IL-25 levels in the two groups.

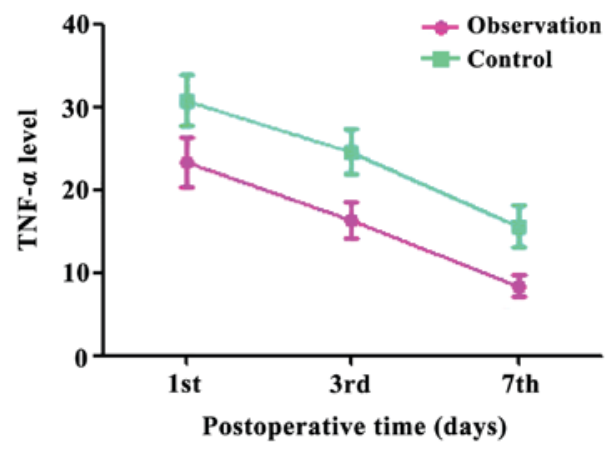

Figure 2. TNF- $\alpha$ level in the two groups.

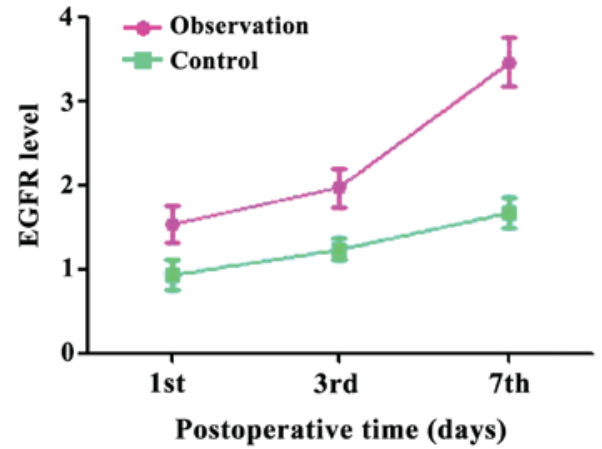

Figure 3. EGFR levels in the two groups.

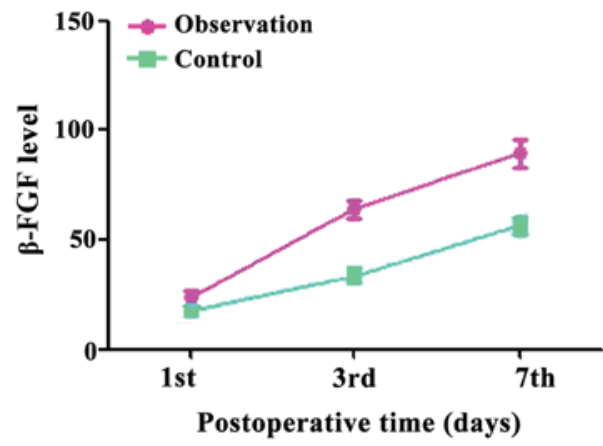

Figure 4. $\beta$-FGF levels in the two groups.

Table V. PoSSe scores.

\begin{tabular}{lccrr}
\hline Item & Observation group $(\mathrm{n}=36)$ & Control group $(\mathrm{n}=36)$ & t-value & P-value \\
\hline Food & $5.76 \pm 2.78$ & $7.96 \pm 2.18$ & 3.763 & 0.0004 \\
Language & $1.17 \pm 0.63$ & $2.57 \pm 0.93$ & 7.478 & $<0.0001$ \\
Felling & $0.83 \pm 0.36$ & $1.44 \pm 0.76$ & 4.325 & $<0.0001$ \\
Swelling & $3.28 \pm 1.57$ & $4.76 \pm 2.06$ & 3.428 & 0.0010 \\
Pain & $4.16 \pm 2.01$ & $6.23 \pm 1.01$ & 5.521 & $<0.0001$ \\
Nausea & $0.21 \pm 0.12$ & $0.91 \pm 0.21$ & 17.365 & $<0.0001$ \\
Daily living & $1.38 \pm 0.34$ & $3.38 \pm 0.54$ & 18.805 & $<0.0001$ \\
\hline
\end{tabular}

$56.47 \pm 4.35 \mathrm{pg} / \mathrm{ml}$. The values were similar in the two groups at day 1 , but the values in the experimental group were significantly higher at days 3 and 7 (Fig. 4).

Quality of life. One week after surgery, the comparison of quality of life for the two groups showed that the experimental group scored better than the control group in all items (food, language, feeling, swelling, pain, nausea, and daily living). The differences were statistically significant (Table V).

\section{Discussion}

The occurrence rate of complications after extraction of third molars can reach up to $20 \%$. Therefore, effective prevention of complications in these procedures has become a key priority for dentists (8). Postoperative complications include pain, dry socket, face swelling, limited mouth opening, and other. These symptoms typically last for seven days, causing serious impact on the daily life of patients (9). Pain results from damaged tissues, which irritates the nerves. Destruction of tissue during surgery leads to edema and swelling of the face as part of the normal reactive edema. Moderate swelling is a protective reaction to trauma; however, excessive swelling has damaging consequences and even leads to infection $(10,11)$. The mechanism explaining the limited mouth opening is that cutting soft tissue during surgery irritates the temporal tendon and the muscle in nasal alar, causing a reflex spasm (12). Clinical treatment of complications after tooth extraction include cold-hot compress, drainage tube, and oral administration of nonsteroidal anti-inflammatory drugs. These treatments need to extend for a period after surgery to shorten the durations of pain, swelling, and limited mouth opening. These complications affect the normal administration of chemotherapy in patients with hematological tumors and may even lead to 
chemotherapy failure. Therefore, it is especially important to identify convenient and effective treatments for these complications (13). Bromelain is a good anti-inflammatory drug that can promote wound repair. Our results suggest that patients on bromelain showed obvious improvement in postoperative pain, swelling, and mouth opening. The quality of life in the bromelain group was higher than in the control group.

The inflammatory response is the most basic reaction to injuries and is a necessary stage for injury repair after third molar extraction (14). The stress response of tissue after surgery will result in the activation of IL-25 and TNF- $\alpha$, which can be detected in serum. IL-25 is a Th2-type inflammatory factor that can strengthen the Th2 immune response. Meanwhile, various types of chemotactic factors will gather at the inflammation site and worsen the inflammatory response. TNF- $\alpha$ activates genes related to the inflammatory reaction, promotes hyperplasia of macrophages, and worsens the stress response $(15,16)$. Our results show that IL-25 and TNF-c were lower in the bromelain group than in the control group. This is because bromelain can not only clear the wound during the inflammatory response but also downregulate IL-25 and TNF- $\alpha$, relieving the inflammatory reaction at the wound surface.

Patients with hematological tumors receive extraction of the third molar during chemotherapy. Rapid repair of the wound after surgery is critical for the success of later chemotherapy rounds. EGFR can promote cell division, increase cell migration, promote wound healing, and improve the quality of tissue repair. EGFR selectively gathers with epidermal cells, inflammatory cells, and fibroblasts and forces their migration towards the wound site. EGFR also promotes cell division and proliferation $(17,18)$. $\beta$-FGF can stimulate the differentiation and proliferation of fibroblasts, improve the level of collagen, increase the growth and epithelization speed of granulation tissue, and induce the generation of microvessels. $\beta$-FGF belongs to one of the most active angiogenesis factors and is used as a marker for the quality and speed of wound healing (19). Our research indicates that EGFR and $\beta$-FGF were elevated in the bromelain group due to its ability to regulate the expression of EGFR and $\beta$-FGF, promote the proliferations of fibroblasts, endothelial cells, and epithelial cells, increase the growth and epithelization speed of granulation tissue, develop new capillaries, degrade excess fibers, and increase the quality and speed of wound healing (20).

In conclusion, bromelain can reduce complications after third molar extraction, including pain, swelling, and limited mouth opening. This is an important advantage for patients undergoing chemotherapy for hematological tumors. Besides, bromelain can promote the recovery effect, improve the quality of life after surgery, and its administration is convenient, easy, economic, and has non-invasive characteristics that deserve wider clinical attention and application.

\section{References}

1. Zor ZF, Isik B and Cetiner S: Efficacy of preemptive lornoxicam on postoperative analgesia after surgical removal of mandibular third molars. Oral Surg Oral Med Oral Pathol Oral Radiol 117: 27-31, 2014.

2. Carvalho RW, Araújo-Filho RC and Vasconcelos BC: Adverse events during the removal of impacted maxillary third molars. Int J Oral Maxillofac Surg 43: 1142-1147, 2014.
3. Alcântara CE, Falci SG, Oliveira-Ferreira F, Santos CR and Pinheiro ML: Pre-emptive effect of dexamethasone and methylprednisolone on pain, swelling, and trismus after third molar surgery: A split-mouth randomized triple-blind clinical trial. Int J Oral Maxillofac Surg 43: 93-98, 2014.

4. Díaz Gómez L, Seguro Fernandez A, Jaen Olasolo J, Villanego Beltran I, Diaz Diaz V, Gonzalez Calvo E, Ingunza Baron L, Gutierrez Bayard L, Salas Buzon MC and Garduño S: EP-1143: Splenic irradiation as treatment modality in neoplastic hematological disorders. Radiother Oncol 119 (Suppl 1): 546, 2016. http:// www.thegreenjournal.com/article/S0167-8140(16)32393-3/fulltext.

5. Hegde AM, Joshi S, Rai K and Shetty S: Evaluation of oral hygiene status, salivary characteristics and dental caries experience in acute lymphoblastic leukemic (ALL) children. J Clin Pediatr Dent 35: 319-323, 2011.

6. Bhatnagar P, Pant AB, Shukla Y, Panda A and Gupta KC: Hyaluronic acid grafted PLGA copolymer nanoparticles enhance the targeted delivery of bromelain in Ehrlich's ascites carcinoma. Eur J Pharm Biopharm 105: 176-192, 2016.

7. de la Barrera-Núñez MC, Yáñez-Vico RM, Batista-Cruzado A Heurtebise-Saavedra JM, Castillo-de Oyagüe R and TorresLagares D: Prospective double-blind clinical trial evaluating the effectiveness of Bromelain in the third molar extraction postoperative period. Med Oral Patol Oral Cir Bucal 19: e157-e162, 2014.

8. Aravena PC, Astudillo P and Manterola C: Design of a scale for measuring post-surgical complications in third molar surgery. Int J Oral Maxillofac Surg 43: 1008-1014, 2014.

9. Ghaeminia H, Hoppenreijs TJM, Xi T, Fennis JP, Maal TJ, Bergé SJ and Meijer GJ: Postoperative socket irrigation with drinking tap water reduces the risk of inflammatory complications following surgical removal of third molars: A multicenter randomized trial. Clin Oral Investig 21: 71-83, 2017.

10. Quiding H, Jonzon B, Svensson O, Webster L, Reimfelt A, Karin A, Karlsten R and Segerdahl M: TRPV1 antagonistic analgesic effect: A randomized study of AZD1386 in pain after third molar extraction. Pain 154: 808-812, 2013.

11. Sortino F and Cicciù M: Strategies used to inhibit postoperative swelling following removal of impacted lower third molar. Dent Res J Isfahan 8: 162-171, 2011.

12. Trindade PAK, Giglio FPM, Colombini-Ishikiriama BL, Calvo AM, Modena KC, Ribeiro DA, Dionísio TJ, Brozoski DT, Lauris JR, Faria FA, et al: Comparison of oral versus sublingual piroxicam during postoperative pain management after lower third molar extraction. Int J Oral Maxillofac Surg 40: 292-297, 2011.

13. Isiordia-Espinoza MA, de Jesús Pozos-Guillén A and AragonMartinez OH: Analgesic efficacy and safety of single-dose tramadol and non-steroidal anti-inflammatory drugs in operations on the third molars: A systematic review and meta-analysis. Br J Oral Maxillofac Surg 52: 775-783, 2014.

14. Bello SA, Adeyemo WL, Bamgbose BO, Obi EV and Adeyinka AA: Effect of age, impaction types and operative time on inflammatory tissue reactions following lower third molar surgery. Head Face Med 7: 8, 2011.

15. Swaidani S, Bulek K, Kang Z, Gulen MF, Liu C, Yin W, Abbadi A, Aronica M and Li X: T cell-derived Actl is necessary for IL-25-mediated Th2 responses and allergic airway inflammation. J Immunol 187: 3155-3164, 2011.

16. Billeter AT, Hellmann JL, Bhatnagar A and Polk HC Jr: Transient receptor potential ion channels: Powerful regulators of cell function. Ann Surg 259: 229-235, 2014.

17. Morgillo F, Martinelli E, Troiani T, Orditura M, De Vita F and Ciardiello F: Antitumor activity of sorafenib in human cancer cell lines with acquired resistance to EGFR and VEGFR tyrosine kinase inhibitors. PLoS One 6: e28841-e28841, 2011.

18. Maretzky T, Evers A, Zhou W, Swendeman SL, Wong PM, Rafii S, Reiss K and Blobel CP: Migration of growth factorstimulated epithelial and endothelial cells depends on EGFR transactivation by ADAM17. Nat Commun 2: 229, 2011.

19. Komura M, Komura H, Konishi K, Ishimaru T, Hoshi K, Takato T, Tabata Y and Iwanaka T: Promotion of tracheal cartilage growth by intra-tracheal injection of basic fibroblast growth factor (b-FGF). J Pediatr Surg 49: 296-300, 2014.

20. de Oliveira Caetano GA, Villela SDJ, de Oliveira MMNF, de Paula Leonel F and Tamy WP: Particle passage kinetics and neutral detergent fiber degradability of silage of pineapple waste (aerial parts) under different packing densities. Rev Bras Zootec 43: 49-53, 2014. http://www.scielo.br/scielo.php?script=sci_arttext \&pid=S1516-35982014000100008 International (CC BY-NC-ND 4.0) License. 